\title{
Inventory Support System for Retail Shop
}

\author{
Rinabi Tanamal ${ }^{1, *}$, Yanuar Nurdiansyah ${ }^{2}$, and Firdaus Firdaus ${ }^{3}$ \\ ${ }^{1}$ Information Systems Department, Faculty of Information Technology, Universitas Ciputra, \\ Citraland CBD Boulevard, Surabaya, 60219, Indonesia \\ ${ }^{2}$ Program Study of Information Technology, University of Jember, Jl. Kalimantan 37, \\ Jember 68121, Indonesia \\ ${ }^{3}$ Advances Informatics School, Universiti Teknologi Malaysia, Level 5, Menara Razak, \\ Jl. Sultan Yahya Petra, 54100 Kuala Lumpur, Malaysia
}

\begin{abstract}
Nowadays having a traditional way recording inventory were very troublesome. Inventory stock is very important when someone run a retail business. If they are not managing inventory well, they will be experiencing losses as if they supply too much, it will risk damaging the stocks and may spending too much storage costs, and vice versa, if the supplies are not sufficient then the customer needs cannot be fulfilled and they will lose profits. Therefore, demand for next period should be estimated, so that customer demand can still be met and they are not bearing the cost of having too many stocks. Shop XYZ is a retail business that sells household daily needs, and they don't know exact number of items in the warehouse. With these problems, this research aims to create procedures and how to forecast reorder quantity of each selected items.
\end{abstract}

Keywords: Inventory management, inventory stock, retail business, standard operating procedures, stock control

\section{Introduction}

The common problem with common old-fashioned store is still using a manual system for maintaining their data, for example manually recording invoice of customer and supplier as well as maintaining customer data. This XYZ store owner didn't know the exact amount of every item in the warehouse, causing several items stacked in the warehouse and unable to sold. When the goods are stock out, the owner had to go to other town to buy items, and it often happens. Nowaday many things have changed when technology updated constantly and has provided a good experience to most consumers [1]. Therefore, they hope good solution that can solve these problems with using technology. To answer the problem then it is necessary to define the research problems which are:

i. How to use better inventory management system in XYZ Shop?

ii. How to forecast an inventory before running out?

Benefits of this research is to help Shop XYZ to improved performance in terms of monitoring inventory, by improving the management of inventory, and providing good advice in procurement quantity. The methodology will be applied to the manufacture on this research are:

*Corresponding author: r.tanamal@ ciputra.ac.id 
i. Interviewing with the owners of the Shop XYZ.

ii. Literature study on the Demand Forecasting and Safety Stock.

iii. Designing Standard Operating Procedure for the shop.

\section{Literature review}

\subsection{Inventory}

Inventory is needed in all operation for assembly, production, shop supplies or sales or sales to a customer [2]. Supplies are very important role because it is directly to the production process that running at a company. Inventory must be maintained on purpose meet the needs of the market, if the good is stock out, the customer would be disappointed and they would not buy on them and they might lose profits. A poor inventory management systems may be indicated by the failure production plans, poor forecast, and inadequate performance reporting [3].

\subsection{Forecasting demand}

Demand Forecasting is a term define more recently as forecast of demand for items in stock. The demand are from customers who want to purchase the item for immediate use [4].

\subsubsection{Simple exponential smoothing}

Simple Exponential Smoothing is a method of forecasting that is easy to use and has been successfully implemented in several different types of companies to be used as a reference forecast demand. Exponential Smoothing first idea was founded by Robert G. Brown about the year 1944. Jay Hayzer explain Simple Exponential Smoothing can be written by the formula in Equation (1) [5]:

$$
\mathrm{F}_{\mathrm{t}}=\mathrm{F}_{\mathrm{t}-1}+\alpha\left(\mathrm{A}_{\mathrm{t}-1}-\mathrm{F}_{\mathrm{t}-1}\right)
$$

Where $F_{t}$ is the new forecast value, $F_{t-1}$ is the forecast value of the previous period, $\alpha$ is the smoothing constant of value 0 to 1 , and $A_{t-1}$ is the demand of the previous period.

\subsubsection{Forecast error}

Forecast Error is a measure of forecasting accuracy and predictive capability is the basis of comparison of the models [6]. There are two methods of evaluation of predictive error that will be used in this research, the MAD and MAPE. In addition to the calculation of forecast accuracy.

\subsubsection{MAD (mean absolute deviation).}

MAD is defined as Equation (2):

$$
\mathrm{MAD}=\frac{\sum \mid \text { Actual }- \text { Forecast } \mid}{n}
$$

This value is computed by taking the sum of the absolute values of the individual forecast errors and dividing by the number of periods of data (n). MAD good or bad it all 
depends on the MAD for other forecasting approaches. A low MAD is better because this study want to minimize MAD value [7].

\subsubsection{MAPE (mean absolute percentage error).}

MAPE is defined as Equation (3):

$$
\text { MAPE }=\frac{\sum_{\mathrm{i}=1}^{\mathrm{n}} 100 \mid \text { Actual }- \text { Forecast } \mid}{n}
$$

Where $n$ is forecast period. If MAPE calculated value is less than $10 \%$, it is interpreted as excellent accurate forecasting, between $10 \%$ to $20 \%$ good forecasting, between $20 \%$ to $50 \%$ acceptable forecasting and over $50 \%$ inaccurate forecasting [8].

\subsubsection{Safety stock}

Safety stock is extra stock to allow for uneven demand [9]. Safety Stock using the formula that is used by SAP Safety Stock, defined as Equation (4) [10]:

$$
\mathrm{SS}=\mathrm{R} \times \mathrm{MAD} \times \mathrm{W}
$$

Where $\mathrm{R}$ is the service factor $(98 \%=2.05)$, MAD is one forecast error method, and $\mathrm{W}$ is the time of the ordered goods until goods arrive at the warehouse and divided by forecast periods.

\subsubsection{Reorder point (ROP)}

Reorder Point is the inventory level (point) at which action is taken to replenish the stocked item [11]. ROP is given as Equation (5):

$$
\text { Reorder Point }=(\text { Demand } \times \text { Lead Time })+\text { Safety Stock }
$$

Where the demand is the average demand of a month, lead time is the length of the delivery, safety stock is an extra stock to allow for uneven demand.

\section{System design}

\subsection{Interview method}

Interview conducted to the store owner who knows the system and that all information required by researchers. Information needed are:

i. Procurement process

ii. Transactions process

iii. Sales process

iv. Any related problems

Based on the results of interviews conducted, it can be points about the state of the Shop $\mathrm{XYZ}$ are:

i. Shop XYZ is a store that sells glassware and another household appliance.

ii. System transactions that occurred in the Shop XYZ include: transaction ordering goods, entry of goods into the warehouse transactions, transactions of goods to the warehouse, and the sale of goods. 
iii. Procurement system in the Shop XYZ, which is the owner writting down of stock out items by relying on their memories.

iv. Problem in monitoring the inventory in the warehouse.

\subsection{Sampling data}

In this research would have to choose 10 of the 20 categories of fast moving goods, the reason is because goods have a fast turnover of stock, and is a daily need of customers. Based on these criteria, the categories of goods taken, is defined: gayung, gelas, guci, kesed, kursi, panci, periuk, sablukan, termos and timba.

\subsection{Sampling data theoretical calculations for reorder quantity}

\subsubsection{Forecasting demand}

Here are examples of using the simple exponential smoothing for forecasting demand for each month (Table 1).

Table 1. Case in kursi demand forecasts using the simple exponential smoothing.

\begin{tabular}{|c|c|c|c|}
\hline Period & Demand & Forecast with $\alpha=0.1$ & Rounding \\
\hline 1 & 4 & 4 & \\
\hline 2 & 5 & $4+0.1 \times(5-4)=4.1$ & 5 \\
\hline 3 & 7 & $4.1+0.1 \times(7-4.1)=4.39$ & 5 \\
\hline 4 & 1 & $4.39+0.1 \times(1-4.39)=4.05$ & 5 \\
\hline 5 & 3 & $4.05+0.1 \times(3-4.05)=3.94$ & 4 \\
\hline 6 & 6 & $3.94+0.1 \times(6-3.94)=4.15$ & 5 \\
\hline 7 & 5 & $4.15+0.1 \times(5-4.15)=4.23$ & 5 \\
\hline 8 & 7 & $4.23+0.1 \times(7-4.23)=4.5$ & 5 \\
\hline 9 & 5 & $4.5+0.1 \times(5-4.5)=4.55$ & 5 \\
\hline 10 & 6 & $4.55+0.1 \times(6-4.55)=4.69$ & 5 \\
\hline 11 & 8 & $4.69+0.1 \times(8-4.69)=5.02$ & 6 \\
\hline 12 & 7 & \multicolumn{2}{|c}{} \\
\hline
\end{tabular}

So, if you want to see the forecast for demand in the period-13 or next year can be calculated in this case $5.02+0.1 \times(7-5.02)=4.89$ or rounded up the five kursi-chairs.

\subsubsection{Selection of smoothing constant}

Selection of smoothing constants can be determined from the forecast error occurs (Table 2), by comparing the prediction results by using constant between 0.1 to 0.9 and later can be seen where the constant which has the smallest forecast error, the researchers will take that value as smoothing constants in this study.

Table 2. Average MAPE using smoothing constants 0.1 to 0.5 .

\begin{tabular}{|c|l|l|c|c|c|c|c|c|c|c|c|}
\hline$\alpha$ & gayung & gelas & guci & kesed & kursi & panci & periuk & sablukan & termos & timba & $\begin{array}{c}\text { Average } \\
\text { (MAPE) }\end{array}$ \\
\hline 0.1 & 101.7 & 78.49 & 44.44 & 46.16 & 95.42 & 82.26 & 92.18 & 73.888 & 51.8445 & 56.699 & 72.30775 \\
\hline 0.2 & 96.725 & 84.02 & 46.89 & 41.85 & 91.47 & 79.17 & 109.5 & 61.705 & 44.9475 & 57.745 & 71.39975 \\
\hline 0.3 & 93.6 & 88.12 & 47.38 & 37.95 & 88.28 & 82.49 & 120.8 & 58.534 & 45.488 & 58.063 & 72.07464 \\
\hline 0.4 & 91.95 & 90.2 & 45.8 & 40.04 & 85.39 & 86.15 & 128.9 & 58.04 & 48.96 & 57.96 & 73.3431 \\
\hline 0.5 & 91.42 & 90.05 & 42.67 & 42.11 & 83.27 & 88.96 & 132.2 & 59.554 & 50.46 & 57.586 & 73.8246 \\
\hline & & & & & & & & & & minimum & 71.39975 \\
\hline
\end{tabular}


The conclusion of Table 2, 0.2 has the lowest average MAPE. Then the simple exponential smoothing calculations will use 0.2 as smoothing constants.

\subsubsection{Safety stock}

Here are examples of using the Safety Stock:

Table 3. Case in forecasting error of kursi calculation using MAD.

\begin{tabular}{|c|c|c|c|}
\hline Period & Demand & Forecast with $\alpha=0.1$ & Absolute Error \\
\hline 1 & 4 & & \\
\hline 2 & 5 & 4 & 1 \\
\hline 3 & 7 & 4 & 3 \\
\hline 4 & 1 & 5 & 4 \\
\hline 5 & 3 & 5 & 2 \\
\hline 6 & 6 & 4 & 2 \\
\hline 7 & 5 & 5 & 0 \\
\hline 8 & 7 & 5 & 2 \\
\hline 9 & 5 & 5 & 0 \\
\hline 10 & 6 & 5 & 1 \\
\hline 11 & 8 & 5 & 3 \\
\hline 12 & 7 & 6 & 1 \\
\hline
\end{tabular}

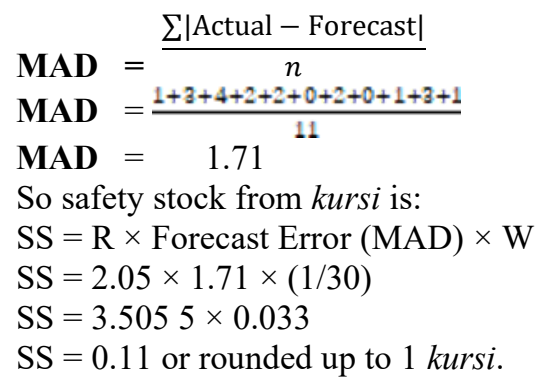

\subsubsection{Reorder quantity}

Before calculating the reorder quantity, first the reorder point must be calculated before, to help see if the store needs to reorder again or not (Equation (5)). If the reorder point is known, the next step is to calculate reorder quantity (Equation (6)) where the number of requests in the future is reduced by the rest of the existing stock.

$$
\text { Reorder Quantity }=\text { Reorder Point }- \text { Current Stock }
$$

Reorder quantity whereby if the value is greater than 0 then it is advisable the store to reorder goods. Demand forecasting of calculation examples (Table 1) and safety stock (Table 3) for the one-month period, showed five forecast kursi-chairs and safety stock number one kursi-chair. From reorder point calculation can be calculated as follows:

Reorder point $=(5 \times 1)+1=6$

Suppose the stores still have stock 10 kursi,

Reorder quantity $=6-10=-4$

It can be seen that the reorder quantity not greater than 0 , so the store is not advisable to order goods.

Suppose the stores still have stock two kursi.

Reorder Quantity $=6-2=4$ 
It can be seen that the reorder quantity, greater than 0 , so it is advisable to order goods store Reorder quantity in amount of four kursi.

\subsubsection{Reorder Report}

Table 4. Example of reorder report.

\begin{tabular}{|c|c|c|c|c|c|}
\hline No & Category & Product Name & QTY. on Hand & Reorder Quantity & Units \\
\hline 1 & Kursi & Kursi minnie DX & 17 & 100 & Pcs \\
\hline 2 & Gelas & Gelas bening & 33 & 220 & Pcs \\
\hline 3 & Sablukan & Sablukan $40 \mathrm{~cm}$ & 47 & 130 & Pcs \\
\hline 4 & Sablukan & Sablukan $60 \mathrm{~cm}$ & 25 & 75 & Pcs \\
\hline 5 & Termos & CKF 300 & 32 & 200 & Pcs \\
\hline 6 & Cetakan & Cetakan awet & 53 & 230 & Pcs \\
\hline 7 & Saringan & Saringan kecil & 16 & 110 & Pcs \\
\hline
\end{tabular}

Report above (Table 4) was made with hope that the owner can determine the amount of remaining stock in the warehouse and decide the amount to be reordered.

\section{Result and discussion}

\subsection{Implementation}

Implement two main procedures namely warehouse stock opname and warehouse Procurement systems.

\subsection{User acceptance testing}

Once the user is implement the procedures and program in XYZ Shop, user acceptance testing was concluded that: User has more aware the quantity in the warehouse, the forecasting programs help user decision making.

\section{Conclusion}

Based on the results of the analysis and system design that has been done, it was concluded that: (i) Thecontrol for better inventory management system has been done; (ii) This research using simple exponential smoothing with a smoothing constant 0.2 , due to the constant range between 0.1 to $0.5,0.2$ constants are constants that have smallest average forecast error. Some of the advice given by this study regarding further research are: (i) Forecasting calculations can use more accurate methods such as double exponential smoothing models or triple exponential smoothing, with extensive data, the trends and the season will be found and can keep pace with the forecast demand fluctuations that occur, or the other words forecasts become more accurate and perfect; (ii) Forecast calculations can be developed to forecast all kinds of goods like fast moving or slow moving. 


\section{References}

1. R. Tanamal. JATIT, 97,20:2406-2418(2019).

https://www.semanticscholar.org/paper/WHAT-IS-THE-MOST-INFLUENTIAL-

FACTOR-ON-DECISIONS-AS-

Tanamal/9fe1fe9c74856a930e3bae29000889a0edbc9ff1

2. E.C. Mercado. Hands-on inventory management. London: CRC Press (2013). p. 55. https://books.google.co.id/books/about/Hands_On_Inventory_Management.html?id=d UW8gmoSDQUC\&redir_esc=y

3. J.K. Shim, J.G. Siegel, A.I. Shim. CFO fundamentals, New Jersey: Wiley (2012). p. 396. https://onlinelibrary.wiley.com/doi/book/10.1002/9781119205111

4. N.T. Thomopoulos. Demand forecasting for inventory control. Switzerland: Springer (2016). p. 2. https://www.springer.com/gp/book/9783319119755

5. J. Heizer, B. Render. Principles of operations management. New Jersey: Prentice Hall (2008). p. 143.

https://books.google.co.id/books/about/Principles_of_Operations_Management.html?i $\mathrm{d}=044 \mathrm{rAQAAMAAJ} \&$ redir esc $=\mathrm{y}$

6. C.B. Bozarth, R.B. Handfield. Introduction to operations and supply chain management. Harlow: Pearson Education Limited (2019). p. 258.

https://www.amazon.com/Introduction-Operations-Supply-Management-

Global/dp/1292093420

7. J.J. Coyle, C.J. Langley, R.A. Novack, B. Gibson. Supply chain management: A logistic prespective. Canada: Cengage Learning (2009). p. 245.

https://www.amazon.com/Supply-Chain-Management-Logistics-

Perspective/dp/1305859979

8. E. Ostertagova, O. Ostertag, Acta Electrotechnica Et Infomatica, 12,3:62-66(2012). http://www.aei.tuke.sk/papers/2012/3/12_Ostertagov\%C3\%A1.pdf

9. M.P.D. Chockalingam. Forecast accuracy and safety stock strategies. [Online] from https://demandplanning.net/documents/dmdaccuracywebVersions.pdf [Accessed 1 August 2019].

10. S. Basis. Safety stock calculation in sap. [Online] from https://www.erpgreat.com/ materials/safety-stock-calculation-in-sap.htm (2009). [Accessed 27 July 2019].

11. R.D. Klassen, L.J. Menor. Cases in operations management. London: Sage Publications (2006). p. 113. https://us.sagepub.com/en-us/nam/cases-in-operationsmanagement/book227303 